\title{
Theoretical modeling and experimental research on the depth of radial material removal for flexible grinding
}

Gang Zheng ( $\sim$ zheng820828@163.com )

Shanghai Institute of Technology

Keyan Chen

Shanghai Institute of Technology

Xiaojian Zhang

Huazhong University of Science and Technology

\section{Research Article}

Keywords: Titanium alloy, Flexible grinding, Depth of radial material removal, Prediction model, Experiment analysis

Posted Date: April 19th, 2021

DOl: https://doi.org/10.21203/rs.3.rs-416728/v1

License: (a) (1) This work is licensed under a Creative Commons Attribution 4.0 International License. Read Full License

Version of Record: A version of this preprint was published at The International Journal of Advanced Manufacturing Technology on July 14th, 2021. See the published version at https://doi.org/10.1007/s00170-021-07535-z. 


\title{
Theoretical modeling and experimental research on the depth of radial material removal for flexible grinding
}

\author{
Gang Zheng ${ }^{1}$, Keyan Chen ${ }^{1}$, Xiaojian Zhang ${ }^{2}$ \\ ${ }^{1}$ School of Mechanical Engineering, Shanghai Institute of Technology, Shanghai, 201418, China \\ ${ }^{2}$ School of Mechanical Science \& Engineering, Huazhong University of Science and Technology, Wuhan, 430074, China
}

Email: zheng820828@163.com

April 2021

\begin{abstract}
Abrasive belt flap wheel has large elastic deformation, which can better fit the surface of aero-engine blades. Reasonable control of the depth of radial material removal can effectively improve the grinding efficiency and profile accuracy of the blade surface. The depth of radial material removal for flexible grinding was studied through the process parameters in this article. First, the material removal rate model was established based on Hertz elastic contact theory and Preston equation. Then, according to the principle of equivalent material removal volume, a noval approach to determine the depth of radial material removal was proposed. Finally, the experiments for both plane and surface were implemented on a vertical machining center. The results indicate that the proposed method can improve the accuracy and consistency for flexible grinding.
\end{abstract}

Keywords: Titanium alloy; Flexible grinding; Depth of radial material removal; Prediction model; Experiment analysis

\section{Introduction}

It is well known that blades are important part of aero-engine. The surface quality and profile accuracy of blades will directly determine the performance of aero-engine. The poor surface quality of blades are prone to fatigue failure, deformation or fracture in the environment of high temperature [1], high pressure and high speed, resulting in short service life, and reducing engine performance, or even damage. Now, the multi-axis CNC milling method is widely applied to blades of aero-engine in domestic and overseas [2], but the surface of blades will have obvious milling residual knife marks. Thus, it is necessary to precisely grind blades after milling process [3].Therefore, it is necessary to use the grinding technology to remove residual margin in order to obtain the better surface quality.[4] At present, the grinding technology of blades is still mainly manual grinding. However, manual grinding has disadvantages such as low efficiency, poor consistency of machining accuracy, and high labor intensity. So, it is very important to develop a new grinding technology in the field of aero-engine blades machining.

Zhang et al. [5] proposed a collision-free planning algorithm for the robot's grinding path, which reduced the number of collision detections and improved efficiency of grinding. Ding et al. [6] based on the automatic polishing system of industrial robots, a polishing method with force-displacement coupling control is proposed, which can effectively achieve concave surface polishing. Tian et al. [7] proposed the algorithm for generating the position and posture of the robot tool and the tool gravity compensation algorithm to achieve constant polishing pressure control and improve the quality of the processed surface. ZhsAO et al. [8] proposed a dual-mode switching composite adaptive strategy based on fuzzy neural network to achieve high-precision control of polishing force, improved blade processing accuracy and surface consistency. Xiao and Huang [9] established a life-cycle material removal (LCMR) model based on abrasive belt grinding, which can effectively predict the material removal rate during machining. Zou et al. [10] used minimum quantity lubrication technology under appropriate lubrication and grinding parameters to effectively improve the surface quality of the abrasive belt after grinding. The above methods are all based on robots or abrasive belt CNC machine tools, but the robot stiffness is poor and the grinding track error is large, which is not suit- 
able for machining high-precision parts. And, the abrasive belt $\mathrm{CNC}$ machine tool is not suitable for machining the blisk due to the large size of the grinding head, which is easy to interfere with the blade.

Hung et al. [11] conducted grinding experiments on Ti-6Al-4V with CBN wheel under different grinding parameters. It was found that feed rate, radial grinding depth and cooling conditions had significant effects on the roughness, and wet grinding produced less defects. Shi et al. [12] studied a new high thermal conductivity vitrified bond CBN grinding wheel to improve grinding temperature, grinding force and processing surface quality. Dai et al. [13] studied the effect of rotation speed on grinding performance, and performed high-speed grinding experiments with ceramic CBN wheel. Under given experimental conditions, the optimal rotation speed was determined and the surface roughness was reduced to less than $0.4 \mu \mathrm{m}$. Ding et al. [14] compared the high-speed grinding performance of Inconel 718 with polycrystalline CBN and monocrystalline CBN. These studies are based on the rigid grinding wheel. The rigid grinding wheel can't fit the blade surface well, which easily causes oversold and undersold, resulting in poor surface accuracy and contour consistency.

As a new type of grinding method, the abrasive belt flap wheel grinding has the advantages of simple structure and small volume, which can be used for machining narrow inlet and outlet channels of blisk on five-axis CNC machine tools [15]. In addition, because the abrasive belt flap wheel has good ductility when rotating, it can be closely attached to the surface of blade, thereby ensuring the consistency of blade profile. Huai et al. [16,17] optimized the abrasive belt flap wheel grinding process parameters and improved the polishing quality and efficiency through the roughness prediction model and blade adaptive flexible polishing path planning method. Zhang et al. [18] used the response surface method to establish the roughness prediction model and optimized the optimal grinding process parameters. Zhao et al. [19] obtained the best process parameters through single factor experiments and quadratic regression methods, which significantly improved the processing quality. The above researches must actually measure the grinding force, the grinding force value during grinding is small, and there will be greater noise when the CNC machine tool is running, which will affect the accuracy of the grinding force signal collection. Therefore, in order to accurately control the surface profile accuracy, the actual grinding depth in the radial direction is studied. First, the material removal rate model was established based on Hertz elastic contact theory [20-22] and Preston equation [23].Then, according to the principle of equivalent material removal volume, a noval approach to determine the depth of radial material removal was proposed. Finally, the experiments for both plane and surface were implemented on a vertical machining center. The results indicate that the proposed method can improve the accuracy and consistency for flexible grinding.

\section{Depth of radial material removal model}

\subsection{Grinding mechanism of the abrasive belt flap wheel}

The abrasive belt flap wheel is a flexible abrasive tool that bonds the abrasive belt flap to the substrate, which has the characteristics of abrasive belt grinding and flexible grinding, as shown in Fig. 1. In the grinding process, under the action of centripetal force, the radius of the abrasive belt flap wheel will increase with the speed. Then, the abrasive belt flap wheel contacts the surface of workpiece to generate the grinding force, and the size of grinding force directly affects the depth of radial material removal. After the specification of abrasive belt flap wheel is determined, the grinding force can be controlled by the deformation of abrasive belt flap wheel, and because the amount of material removed during the grinding of abrasive belt flap wheel is little, the radial theoretical grinding depth $a_{e}$ can be approximated to the maximum elastic deformation $\delta_{\max }$ of abrasive belt flap wheel, that $\delta_{\max } \approx a_{e}$.

The surface of aero-engine blade is a complex curved surface with great curvature variation, but the abrasive belt flap wheel with significant elasticity, which can fit the blade surface well. Therefore, the contact zone can still be considered as the elastic contact between elastic cylinder and rigid cylinder. Based on the Hertz elastic contact theory, the relationship between normal grinding force and contact width is shown in Eq. (1). 


$$
\left\{\begin{array}{l}
F_{n}=\frac{\pi E_{w b} b a^{2}}{4 R_{e}} \\
E_{w b}=\left(\frac{1-v_{w}^{2}}{E_{w}}+\frac{1-v_{b}^{2}}{E_{b}}\right)^{-1} \\
\frac{1}{R_{e}}=\frac{1}{R_{1}} \pm \frac{1}{R_{2}}
\end{array}\right.
$$

where $b$ is the contact length, $a$ is the half-contact width, $v_{w}$ is the Poisson's ratio of workpiece, $E_{w}$ is the elastic modulus of workpiece, $v_{b}$ is the Poisson's ratio of abrasive belt flap wheel, $E_{b}$ is the elastic modulus of abrasive belt flap wheel, $R_{l}$ is the radius of abrasive belt flap wheel, $R_{2}$ is the curvature radius of workpiece at contact point.

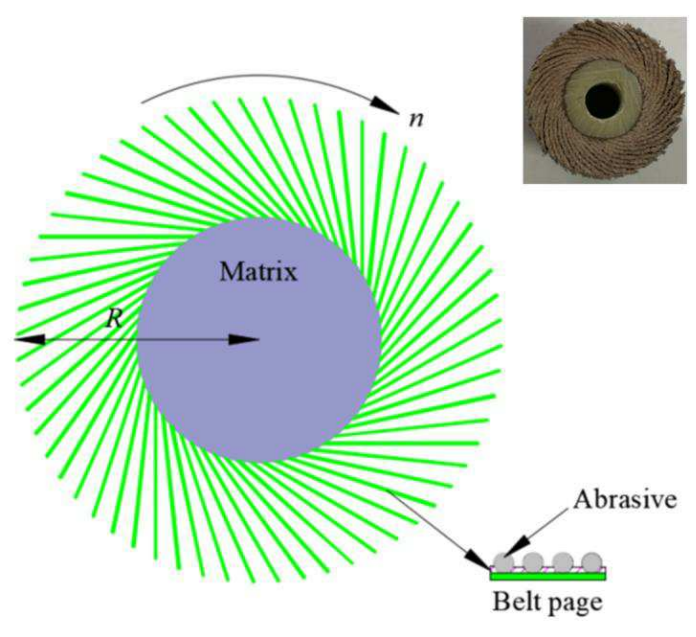

Fig.1 Structure of abrasive belt flap wheel

\subsection{Average grinding pressure}

The material removal model with the abrasive belt flap wheel is established based on Preston equation, as shown in Eq. (2). Equation (2) reveals that when other grinding parameters are determined, the material removal rate is mainly affected by the pressure, which is the grinding force $F_{n}$. The grinding force $F_{n}$ is mainly affected by the radial theoretical grinding depth $a_{e}$. Therefore, in the abrasive belt flap wheel grinding, maintaining a constant radial theoretical grinding depth is important for the stability of the material removal rate.

$$
\begin{gathered}
\frac{d h}{d t}=K P V \\
P=\frac{F_{n}}{A}
\end{gathered}
$$

where, $h$ is the thickness of material removal, $K$ is the Preston coefficient, determined by the material properties of abrasive belt flap wheel and the material properties of workpiece, $V$ is the relative motion speed of abrasive belt flap wheel and workpiece, $A$ is the contact zone.

During the machining process, the material removal rate distribution of the single contact zone of abrasive belt flap wheel and workpiece is a curved surface. For the convenience of research, the average material removal rate of single contact zone is taken as the material removal rate of abrasive belt flap wheel, as shown in Eq. (4). 


$$
H_{m}=K P_{m} V_{m}
$$

where, $P_{m}$ is the average grinding pressure in contact zone, $V_{m}$ is the average relative motion speed.

Figure $2 \mathrm{a}$ shows the contact between abrasive belt flap wheel and convex surface of workpiece. Set the point $M_{l}$ coordinates as $\left(x_{m l}, y_{m l}\right)$, it can be seen from Fig.2a that the point $O_{1}$ coordinate is $\left(0, R_{1}-\delta_{\max }\right)$, the point $O_{2}$ coordinate is $\left(0,-R_{2}\right)$. From the point $M_{l}$ on both the surface of abrasive belt flap wheel and the surface of workpiece, as shown in Eq. (5).

$$
\left\{\begin{array}{l}
x_{m 1}^{2}+\left(y_{m 1}-R_{1}+\delta_{\max }\right)^{2}=R_{1}^{2} \\
x_{m 1}^{2}+\left(y_{m 1}+R_{2}\right)^{2}=R_{2}^{2}
\end{array}\right.
$$

where, $\delta_{\max }$ is the maximum deformation of the abrasive belt flap wheel.

Hence, from Eq. (3) and Eq. (5), and Figure 2a shows that the point $M_{l}$ is on the left side of coordinate system, so the value of $x_{m l}$ is shown in Eq. (6).

$$
\begin{aligned}
x_{m 1}=- & -\left(\frac{2 R_{1} \delta_{\max }-\delta_{\max }^{2}}{2 \delta_{\max }-2 R_{1}-2 R_{2}}\right)^{2} \\
& \left.-\frac{2 R_{1} R_{2} \delta_{\max }-R_{2} \delta_{\max }^{2}}{\delta_{\max }-R_{1}-R_{2}}\right]^{\frac{1}{2}}
\end{aligned}
$$

Contact half width of the convex surface is:

$$
\begin{aligned}
a=\left|x_{m 1}\right|= & -\left(\frac{2 R_{1} \delta_{\max }-\delta_{\max }^{2}}{2 \delta_{\max }-2 R_{1}-2 R_{2}}\right)^{2} \\
& \left.-\frac{2 R_{1} R_{2} \delta_{\text {max }}-R_{2} \delta_{\max }^{2}}{\delta_{\text {max }}-R_{1}-R_{2}}\right]^{\frac{1}{2}}
\end{aligned}
$$

According to the Equations (1), (3) and (7), $P_{m l}$ can be written as:

$$
\begin{aligned}
P_{m 1}=\frac{\pi E_{w b}}{8 R_{e}}[ & -\left(\frac{2 R_{1} \delta_{\max }-\delta_{\max }^{2}}{2 \delta_{\max }-2 R_{1}-2 R_{2}}\right)^{2} \\
& \left.-\frac{2 R_{1} R_{2} \delta_{\max }-R_{2} \delta_{\max }^{2}}{\delta_{\max }-R_{1}-R_{2}}\right]^{\frac{1}{2}}
\end{aligned}
$$

Figure $2 \mathrm{~b}$ shows the contact between abrasive belt flap wheel and concave surface of workpiece. Similarly, the average pressure of the contact between the abrasive belt flap wheel and concave surface is shown in Eq. (9).

$$
\begin{aligned}
P_{m 2}=\frac{\pi E_{w b}}{8 R_{e}}[ & -\left(\frac{2 R_{1} \delta_{\max }-\delta_{\text {max }}^{2}}{2 \delta_{\max }-2 R_{1}+2 R_{2}}\right)^{2} \\
& \left.+\frac{2 R_{1} R_{2} \delta_{\text {max }}-R_{2} \delta_{\text {max }}^{2}}{\delta_{\text {max }}-R_{1}+R_{2}}\right]^{\frac{1}{2}}
\end{aligned}
$$




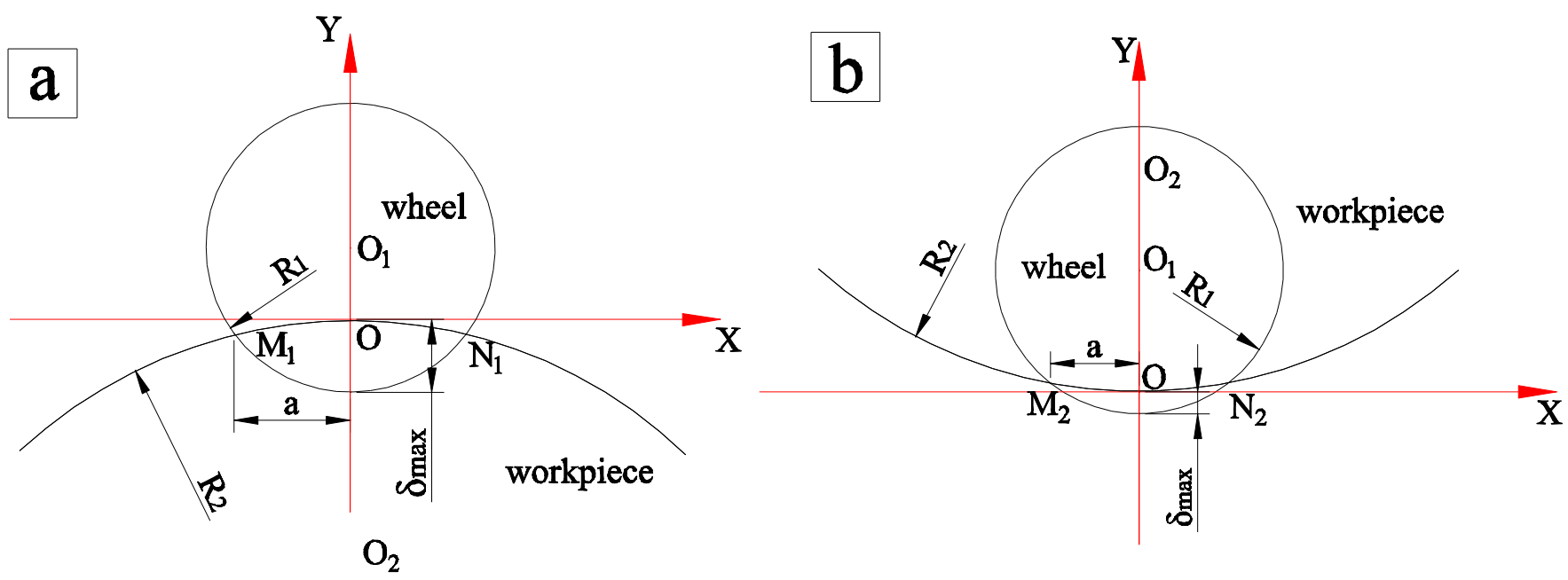

Fig.2 Contact pressure between abrasive belt flap wheel and workpiece

Figure 3 shows the variation law of pressure in contact zone with deformation of the abrasive belt flap wheel. It is consistent with the actual situation. The reason is that within the deformation range of the abrasive belt flap wheel, the contact force increases with the increase of the deformation, and the contact area is also increasing.

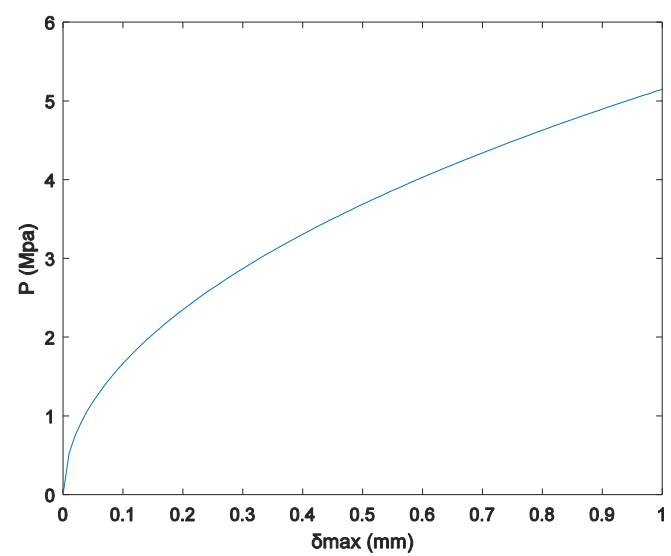

Fig.3 The relationship between contact pressure and deformation

\subsection{Relative grinding speed}

In the grinding process, the abrasive belt flap wheel will produce certain elastic deformation due to the grinding force. Therefore, the linear speed at each point of the contact zone is determined by the speed and deformation of the abrasive belt flap wheel, as shown in Eq. (10).

$$
V_{e}=2 \pi n\left(R_{1}-\delta\right)
$$

where, $V_{e}$ is the linear speed of contact point of the abrasive belt flap wheel, $n$ is the speed of the abrasive belt flap wheel, $\delta$ is the deformation of abrasive belt flap wheel, respectively, $0 \leq \delta \leq a_{e}$. Since the grinding feed rate $V_{w}$ is much less than the linear speed of abrasive belt flap wheel, the linear speed of contact point of the abrasive belt flap wheel can be approximated as the relative motion speed.

Figure 4a shows that when the abrasive belt flap wheel is in contact with the surface of the workpiece, the projection of its 
contact zone on the $X O Z$ plane is a rectangle.

Figure $4 \mathrm{~b}$ and Figure $4 \mathrm{c}$ show the analysis of grinding speed when the abrasive belt flap wheel is in contact with convex surface and concave surface respectively. Suppose point $A$ is any point on the contact zone. According to the geometric relationship in Fig. 4b and Fig. 4c, the speed equa tions of point A on the convex and concave surfaces are shown in Eq. (11) and Eq. (12), respectively.

$$
\begin{aligned}
V_{1}=2 \pi n\left[R_{2}^{2}+\left(R_{1}+R_{2}-\delta_{\max }\right)^{2}\right. \\
\left.-2\left(R_{1}+R_{2}-\delta_{\text {max }}\right) \sqrt{R_{2}^{2}-x^{2}}\right]^{\frac{1}{2}} \\
V_{1}=2 \pi n\left[R_{2}^{2}+\left(R_{2}+\delta_{\text {max }}-R_{1}\right)^{2}\right. \\
\left.-2\left(R_{2}+\delta_{\text {max }}-R_{1}\right) \sqrt{R_{2}^{2}-x^{2}}\right]^{\frac{1}{2}}
\end{aligned}
$$

Therefore, the average relative motion speed of convex surface contact and concave surface contact are shown in Eq. (13) and Eq. (14), respectively.

$$
\begin{aligned}
& V_{1 m}= \frac{\pi n}{a} \int_{-a}^{a}\left[R_{2}^{2}\right. \\
&+\left(R_{1}+R_{2}-\delta_{\max }\right)^{2} \\
&\left.-2\left(R_{1}+R_{2}-\delta_{\max }\right) \sqrt{R_{2}^{2}-x^{2}}\right]^{\frac{1}{2}} d x \\
& V_{1 m}=\frac{\pi n}{a} \int_{-a}^{a}\left[R_{2}^{2}\right. \\
&+\left(R_{2}+\delta_{\max }-R_{1}\right)^{2} \\
&-\left.2\left(R_{2}+\delta_{\max }-R_{1}\right) \sqrt{R_{2}^{2}-x^{2}}\right]^{\frac{1}{2}} d x
\end{aligned}
$$

According to the Equations (4), (8) and (13), $H_{m l}$ can be written as:

$$
\begin{aligned}
H_{m 1}= & \frac{K \pi^{2} n E_{w b}}{8 R_{e}} \int_{-a}^{a}\left[R_{2}^{2}\right. \\
& +\left(R_{1}+R_{2}-\delta_{\max }\right)^{2} \\
& \left.-2\left(R_{1}+R_{2}-\delta_{\text {max }}\right) \sqrt{R_{2}^{2}-x^{2}}\right]^{\frac{1}{2}} d x \\
H_{m 2}= & \frac{K \pi^{2} n E_{w b}}{8 R_{e}} \int_{-a}^{a}\left[R_{2}^{2}\right. \\
& +\left(R_{2}+\delta_{\text {max }}-R_{1}\right)^{2} \\
& \left.-2\left(R_{2}+\delta_{\max }-R_{1}\right) \sqrt{R_{2}^{2}-x^{2}}\right]^{\frac{1}{2}} d x
\end{aligned}
$$


According to the principle of equal material removal volume of the abrasive belt flap wheel during processing, and it is combined with the traditional material removal volume formula, as shown in Eq. (17).

$$
\left\{\begin{array}{l}
H_{v}=a_{p} b V t \\
H_{v}=H_{m} b t d L
\end{array}\right.
$$

where, $H_{v}$ is the material removal volume, $a_{p}$ is the depth of radial material removal, $t$ is the contact time, $d L$ is the unit distance of the abrasive belt flap wheel moving on workpiece.

The relationship between the depth of radial material removal and the material removal rate is obtained, as shown in Eq. (18).

$$
a_{p}=\frac{H_{m}}{V} d L
$$

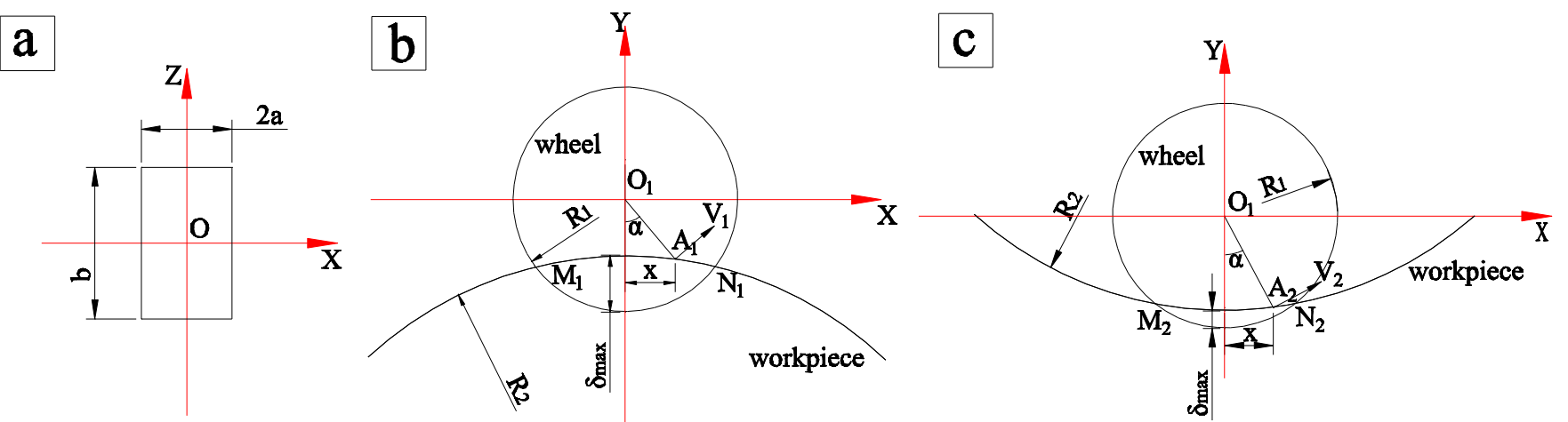

Fig.4 Relative motion speed bewtween abrasive belt flap wheel and workpiece

\section{Verification experiments}

\subsection{Experiment platform}

The reliability of the radial material removal depth model with the abrasive belt flap wheel in the actual machining process is verified through experiments. Process parameters in this experiment are shown in Table 1. The experimental platform is a three-axis vertical machining center VMP-40A, the workpiece material are block of TC4 and cylinders of TC4 with different radii, the abrasive tool is the abrasive belt flap wheel, as shown in Fig. 5a and Fig. 5b. In order to reduce the error of the elastic deformation caused by the speed of the abrasive belt flap wheel in the experiment, it is necessary to measure the relationship between the radius of the abrasive belt flap wheel and the speed before the experiment, as shown in Fig. 6. The surface of block is ground according to the process parameters in Table 2. The height values of surface profile before and after grinding are obtained by WENZEL coordinate measuring machine to calculate the depth of radial material removal. The reverse solution is carried out to determine the coefficient $\mathrm{K}$ of Preston equation in the theoretical model. The average Preston equation coefficient is $K=6.633 \times 10^{-5}$.

Table 1 Grinding parameters

\begin{tabular}{llcc}
\hline Grinding parameters & & & \\
\hline workpiece & Material & TC4 piece & TC4 cylinder \\
& Length $(\mathrm{mm})$ & 340 & $/$ \\
& Width $(\mathrm{mm})$ & 120 & $/$ \\
& Radius $(\mathrm{mm})$ & $/$ & $\mathrm{SiC}$ \\
\hline abrasive belt flap wheel & Abrasive & $\mathrm{SiC}$ & 320 \\
& Mesh $(\#)$ & 320 & 10 \\
& Radius $R_{I}(\mathrm{~mm})$ & 10 & 15
\end{tabular}



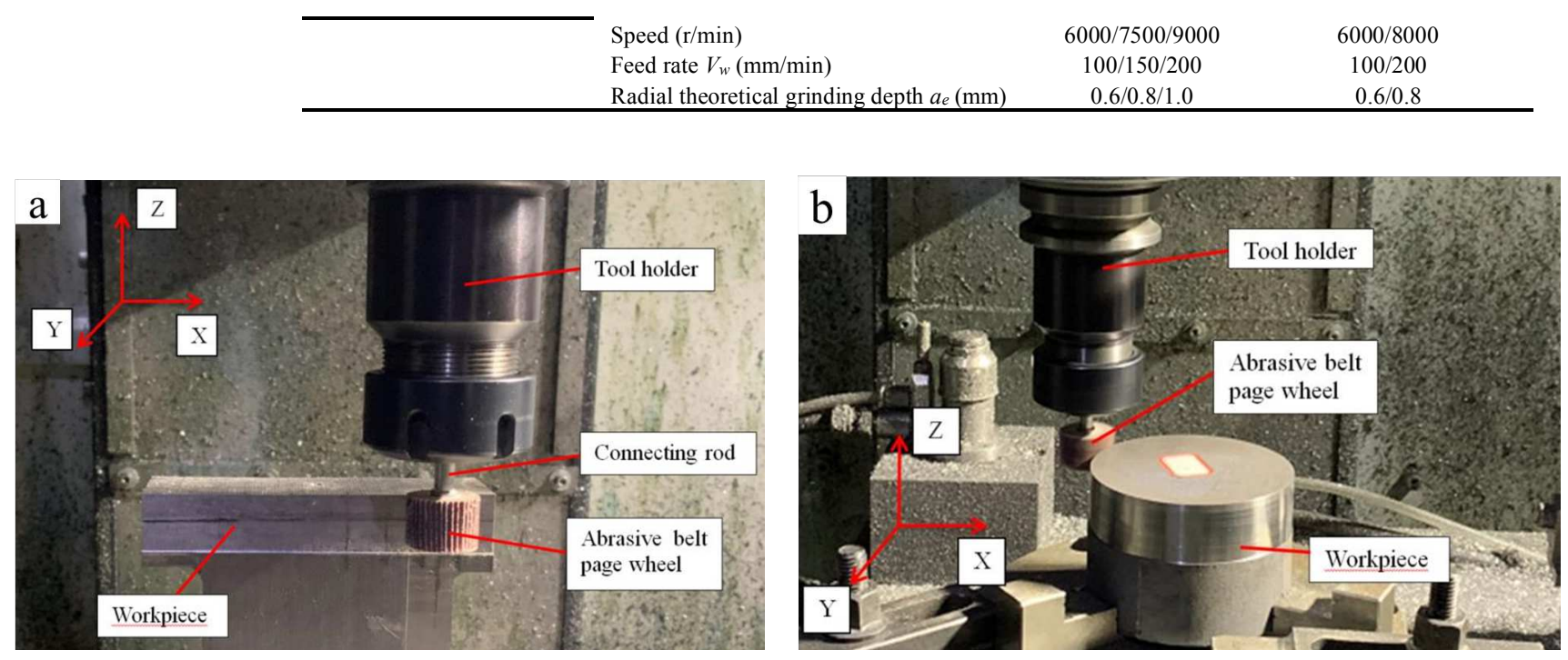

Fig.5 experimental platform

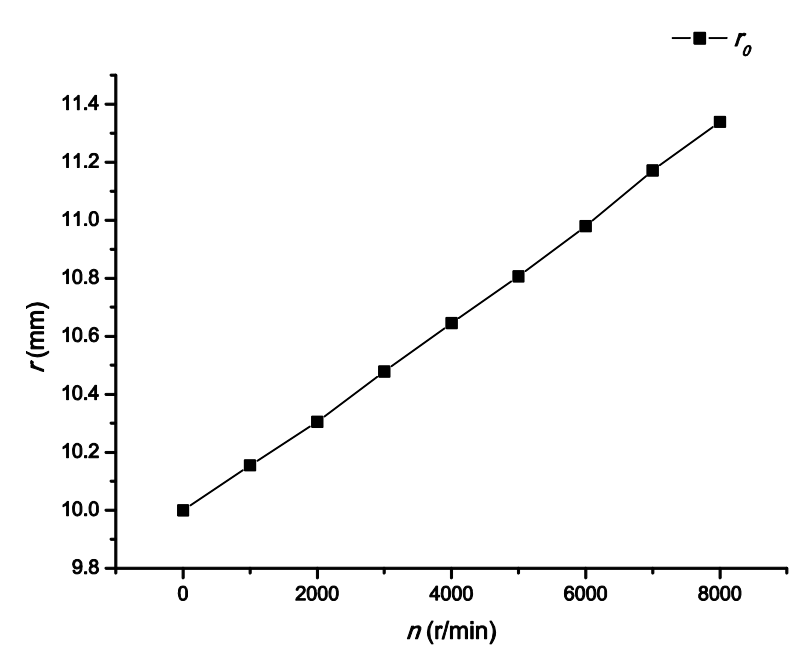

Fig.6 Relationship between $r_{0}$ and $n$

Table 2 Preston coefficient $K$ solution experiment

\begin{tabular}{cccccc}
\hline No. & $n(\mathrm{r} / \mathrm{min})$ & $\begin{array}{c}V_{w} \\
(\mathrm{~mm} / \mathrm{min})\end{array}$ & $a_{e}(\mathrm{~mm})$ & $a_{p}(\mu \mathrm{m})$ & $\mathrm{K}$ \\
\hline 1 & 6000 & 100 & 0.8 & 0.298 & $6.57 \times 10^{-5}$ \\
\hline 2 & 6000 & 100 & 1.0 & 0.338 & $6.65 \times 10^{-5}$ \\
\hline 3 & 8000 & 100 & 0.8 & 0.301 & $6.74 \times 10^{-5}$ \\
\hline 4 & 8000 & 100 & 1.0 & 0.329 & $6.57 \times 10^{-5}$ \\
\hline
\end{tabular}

\subsection{Analysis of results}

Used the WENZEL coordinate measuring machine to measure the block and cylinders with different radii, randomly select five points on the surface of workpiece for measurement, and calculated the average value, as shown in Table 3 and Table 4. Figure $7 \mathrm{a}$ and Figure $7 \mathrm{~b}$ showed the comparison of measured and predicted values. The result showed that the theoretical value was close to the measured value. The average error of the TC4 block was $6.54 \%$, and the average error of the TC4 cylinder was $7.42 \%$, indicated that the difference between the two was not large. The depth of radial material removal model had high reliability for both plane workpieces and cylindrical workpieces were proved. 
The main effect analysis was carried out on the predicted value of the plane and the predicted value of the curved surface, as shown in Figure 8a and 8b. Figure 8a and Figure 8b showed the depth of radial theoretical grinding was the biggest influencing factor, which was consistent with the actual machining. The depth of radial material removal decreased with the increase of speed, mainly because within the deformation range of abrasive belt flap wheel, its radius would increase with the increase of speed. Therefore, under other same parameters, the grinding force became smaller. The feed rate had little effect on the actual grinding depth in the radial direction, because the feed rate was small compared to the linear speed of the contact point. In the curved surface grinding, the difference curvature radius of workpiece would affect the size of contact area, and the pressure in the contact area would be changed, thereby affected the depth of radial material removal.

Table 3 TC4 piece experimental combinations and results

\begin{tabular}{ccccccc}
\hline No. & $\begin{array}{c}n \\
\mathrm{r} / \mathrm{min})\end{array}$ & $\begin{array}{c}V_{w} \\
(\mathrm{~mm} / \mathrm{min})\end{array}$ & $\begin{array}{c}a_{e} \\
(\mathrm{~mm})\end{array}$ & $\begin{array}{c}\text { Measure } a_{p} \\
(\mu \mathrm{m})\end{array}$ & $\begin{array}{c}\text { Predictive } a_{p} \\
(\mu \mathrm{m})\end{array}$ & $\begin{array}{c}\text { Error } \\
(\%)\end{array}$ \\
\hline 1 & 6000 & 100 & 0.6 & 0.237 & 0.26 & -9.7 \\
2 & 6000 & 150 & 0.8 & 0.281 & 0.301 & -7.12 \\
3 & 6000 & 200 & 1.0 & 0.352 & 0.337 & 4.26 \\
4 & 7500 & 100 & 0.8 & 0.305 & 0.298 & 2.3 \\
5 & 7500 & 150 & 1.0 & 0.324 & 0.334 & -3.09 \\
6 & 7500 & 200 & 0.6 & 0.221 & 0.257 & -16.29 \\
7 & 9000 & 100 & 1.0 & 0.306 & 0.33 & -7.84 \\
8 & 9000 & 150 & 0.6 & 0.245 & 0.254 & -3.67 \\
9 & 9000 & 200 & 0.8 & 0.281 & 0.294 & -4.63 \\
\hline
\end{tabular}

Table 4 TC4 cylinder experimental com-

\begin{tabular}{cccccccc}
\hline No. & $\begin{array}{c}R_{2} \\
(\mathrm{~mm})\end{array}$ & $\begin{array}{c}n \\
(\mathrm{r} / \mathrm{min})\end{array}$ & $\begin{array}{c}V_{w} \\
(\mathrm{~mm} / \mathrm{min})\end{array}$ & $\begin{array}{c}a_{e} \\
(\mathrm{~mm})\end{array}$ & $\begin{array}{c}\text { Measure } a_{p} \\
(\mu \mathrm{m})\end{array}$ & $\begin{array}{c}\text { Predictive } a_{p} \\
(\mu \mathrm{m})\end{array}$ & $\begin{array}{c}\text { Error } \\
(\%)\end{array}$ \\
\hline 1 & 10 & 6000 & 100 & 0.6 & 0.346 & 0.379 & -9.54 \\
2 & 10 & 8000 & 200 & 0.8 & 0.468 & 0.437 & 6.62 \\
3 & 12.5 & 6000 & 100 & 0.6 & 0.325 & 0.359 & -10.46 \\
4 & 12.5 & 8000 & 200 & 0.8 & 0.428 & 0.413 & 3.5 \\
5 & 15 & 6000 & 200 & 0.6 & 0.312 & 0.345 & -10.58 \\
6 & 15 & 8000 & 100 & 0.8 & 0.408 & 0.397 & 2.7 \\
7 & 20 & 6000 & 200 & 0.6 & 0.299 & 0.326 & -9.03 \\
8 & 20 & 8000 & 100 & 0.8 & 0.395 & 0.375 & 5.06 \\
9 & 25 & 8000 & 100 & 0.6 & 0.292 & 0.311 & -6.51 \\
10 & 25 & 6000 & 200 & 0.8 & 0.381 & 0.365 & 4.2 \\
11 & 35 & 8000 & 100 & 0.6 & 0.274 & 0.296 & -8.03 \\
12 & 35 & 6000 & 200 & 0.8 & 0.380 & 0.348 & 8.42 \\
13 & 40 & 8000 & 200 & 0.6 & 0.273 & 0.292 & -6.96 \\
14 & 40 & 6000 & 100 & 0.8 & 0.376 & 0.342 & 9.04 \\
15 & 45 & 8000 & 200 & 0.6 & 0.265 & 0.288 & -8.68 \\
16 & 45 & 6000 & 100 & 0.8 & 0.373 & 0.338 & 9.38 \\
\hline
\end{tabular}
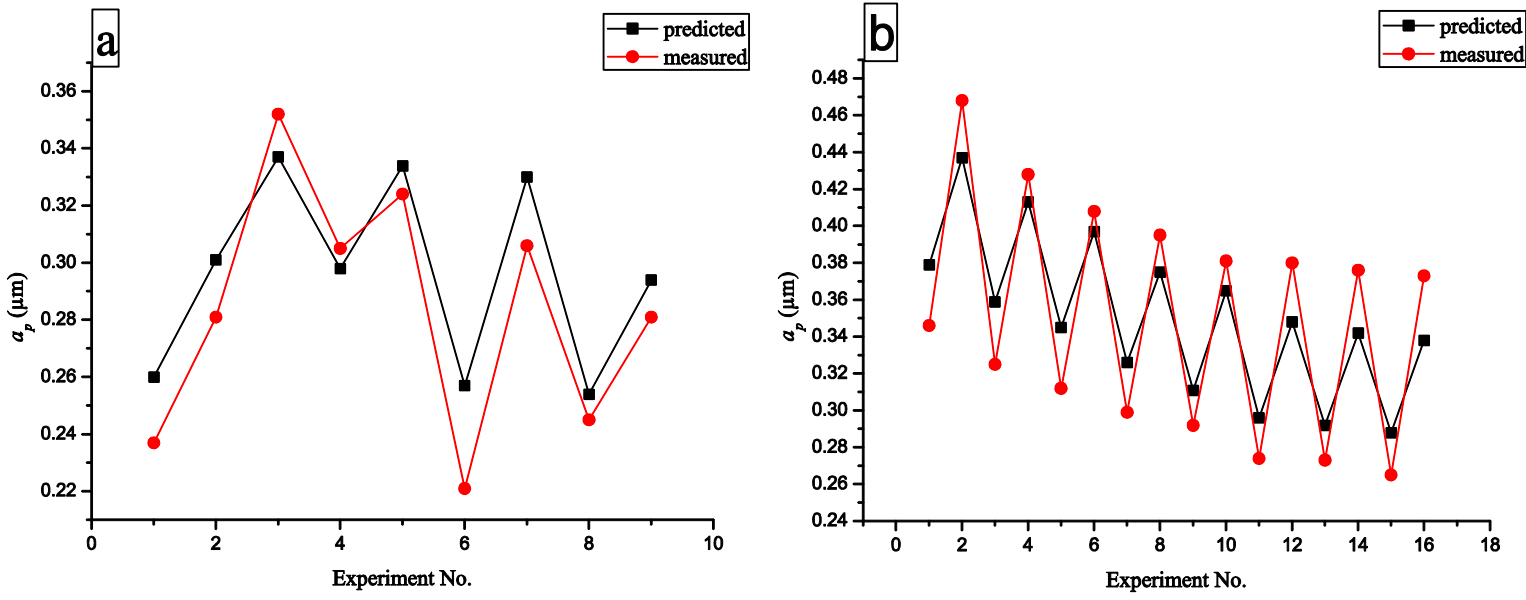

Fig.7 Comparison of measured-predicted values 

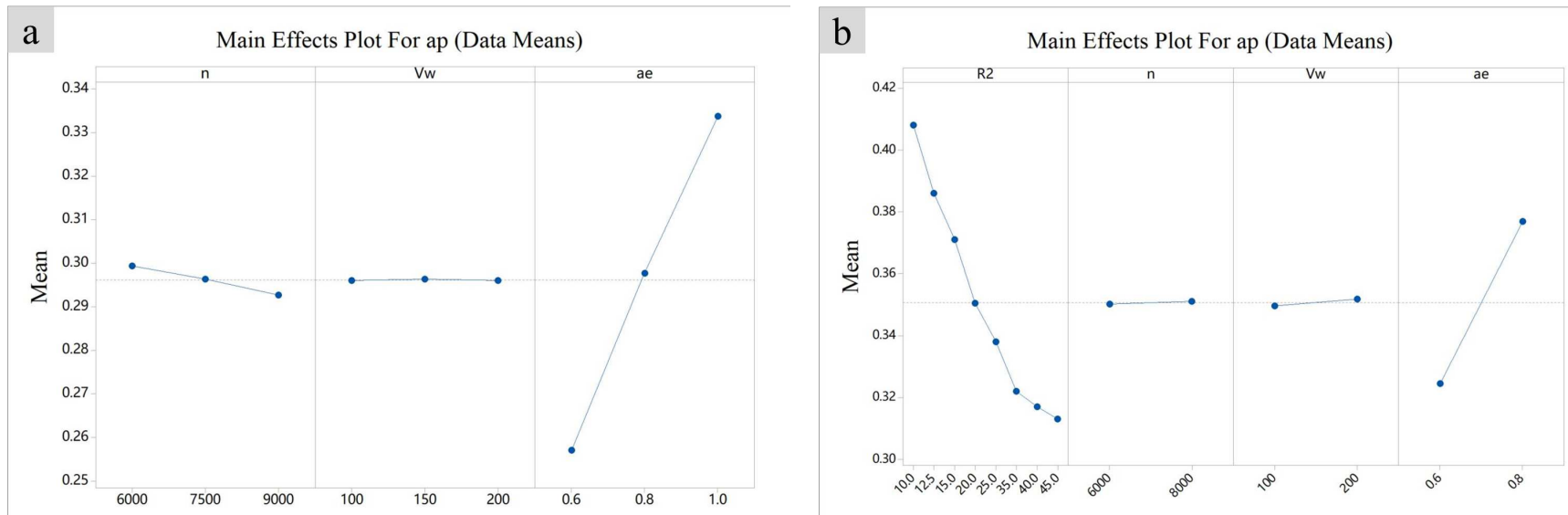

Fig.8 Main effects for each parameter

\section{Conclusions}

(1) Within a certain speed range, the radius of the abrasive belt flap wheel will increase linearly with the increase of speed. The pressure in the contact zone shows a parabolic distribution with the deformation of the abrasive belt flap wheel.

(2) The radial theoretical grinding depth has a great influence on the stability of material removal rate in the grinding of the abrasive belt flap wheels.

(3) Based on the Preston equation and Hertz elastic theory, the relationship between the radial theoretical grinding depth and the material removal rate is derived. And according to the principle of conservation of material removal, the depth of radial material removal model is obtained.

(4) Through the experiment of the amount of grinding material removed by plane and curved surface, the reliability and applicability of the depth of radial material removal model are verified.

(5) Analyzed the influence of speed, feed rate, theoretical radial grinding depth and workpiece curvature radius on the depth of radial material removal, provided a reference for the technical parameters of the abrasive belt flap wheel grinding titanium alloy blades.

\section{Declarations}

\section{Ethical Standards ( Not applicable )}

No conflict of interest exits in the submission of this manuscript, and manuscript is approved by all authors for publication. I would like to declare on behalf of my co-authors that the work described was original research that has not been published previously, and not under consideration for publication elsewhere, in whole or in part.

\section{Authors Contributions ( Not applicable )}

Gang Zheng provided financial support and revision of the paper.

Keyan Chen conducted experiments and data collection, and wrote the paper.

Xiaojian Zhang provided an experimental platform and ideas.

\section{Funding ( Not applicable )}

No funding.

\section{Competing Interests ( Not applicable )}

No competing interests.

\section{Availability of data and materials ( Not applicable )}

All data generated or analysed during this study are included in this published article. 


\section{References}

1. Huang H, Gong Z, Chen X, Zhou L (2002) Robotic grinding and polishing for turbine-vane overhaul. J Mater Process Tech 127:140-145. https://doi.org/10.1016/S0924-0136(02)00114-0

2. HUAI W, Shi Y, Tang H, Lin X (2017) Sensitivity of surface roughness to flexible polishing parameters of abrasive cloth wheel and their optimal intervals. J Mech Sci Technol 31(2):865-873. https://doi.org/10.1007/s12206-017-0140-2

3. Xiao G, Huang Y (2015) Constant-load adaptive belt polishing of the weak-rigidity blisk blade. Int J Adv Manuf Tech 78(9-12):1473-1484. https://doi.org/10.1007/s00170-014-6724-4

4. M. Bigerelle, A. Gautier, B. Hagege and B. Bounichane (2009) Roughness characteristic length scales of belt finished surface, Journal of Materials Processing Technology, 209(20):6103-6116. https://doi.org/10.1016/i.jmatprotec.2009.04.013

5. Zhang T, Su J (2018) Collision-free planning algorithm of motion path for the robot belt grinding system. Int J Adv Robot Syst, $15(4): 172988141879377$. https://doi.org/10.1177/1729881418793778

6. Ding Y, Min X, Fu W, Liang Z L (2018) Research and application on force control of industrial robot polishing concave curved surfaces. P I Mech Eng B-J Eng 233(6):1674-1686. https://doi.org/10.1177/0954405418802309

7. Tian F, Li Z, Lv C, Liu G (2016) Polishing pressure investigations of robot automatic polishing on curved surfaces. Int J Adv Manuf Tech 87(1-4):639-646. https://doi.org/10.1007/s00170-016-8527-2

8. ZhsAO P, Shi Y (2013) Composite adaptive control of belt polishing force for aero-engine blade. Chinese Journal of Mechanical Engineering 26(5):988996. https://doi.org/10.3901/cjme.2013.05.988

9. Xiao G, Huang Y (2017) Experimental research and modelling of life-cycle material removal in belt finishing for titanium alloy. J Manuf Process 30:255-267. https://doi.org/10.1016/i.jmapro.2017.09.030

10. Zou L, Li H, Yang Y, Huang Y (2020) Feasibility study of minimum quantity lubrication assisted belt grinding of titanium alloys. Mater Manuf Process 35:961-968. https://doi.org/10.1080/10426914.2020.1747625

11. Hung P, Dung H, Trung N (2020) The study on surface grinding process of TI-6AL-4V alloy with resinoid cBN grinding wheel. Int J Mod Phys B 34:2040135. https://doi.org/10.1142/s0217979220401359

12. Shi Y, Chen L, Xin H, Yu T, Sun Z (2020) Investigation on the grinding properties of high thermal conductivity vitrified bond CBN grinding wheel for titanium alloy. Int J Adv Manuf Tech 107:1539-1549. https://doi.org/10.1007/s00170-020-05134-y

13. Dai C, Ding W, Zhu J, Xu J, Yu H W (2017) Grinding temperature and power consumption in high speed grinding of Inconel 718 nickel-based superalloy with a vitrified CBN wheel. Precis Eng 52:192-200. https://doi.org/10.1016/i.precisioneng.2017.12.005

14. Ding W, Miao Q, Zhu Y, Xu J, Fu Y (2014) Comparative investigation on wear behavior and self-sharpening phenomenon of polycrystalline cubic boron nitride and monocrystalline cubic boron nitride grains in high-speed grinding. P I Mech Eng B-J Eng 230(4):710-721. https://doi.org/10.1177/0954405414558738

15. Zhang J, Shi Y, Lin X, Li Z (2017) Five-axis abrasive belt flap wheel polishing method for leading and trailing edges of aero-engine blade. Int J Adv Manuf Tech 93(9-12):3383-3393. https://doi.org/10.1007/s00170-017-0717-z

16. Huai W, Shi Y, Tang H, Lin X (2016) Prediction of surface roughness ratio of polishing blade of abrasive cloth wheel and optimization of processing parameters. Int J Adv Manuf Tech 90(1-4):699-708. https://doi.org/10.1007/s00170-016-9397-3

17. Huai W, Shi Y, Tang H, Lin X (2019) An adaptive flexible polishing path programming method of the blisk blade using elastic grinding tools. J Mech Sci Technol 33(7):3487-3495. https://doi.org/10.1007/s12206-019-0643-0

18. Zhang J, Shi Y, Lin X, Li Z (2017) Parameter optimization of five-axis polishing using abrasive belt flap wheel for blisk blade. J Mech Sci Technol 31(10):4805-4812. https://doi.org/10.1007/s12206-017-0928-0

19. Zhao T, Shi Y, Lin X, et al (2014) Surface roughness prediction and parameters optimization in grinding and polishing process for IBR of aero-engine. Int $J$ Adv Manuf Tech 74(5-8):653-663. https://doi.org/10.1007/s00170-014-6020-3

20. Johnson KL (1985) Contact Mechanics. New York: Cambridge University Press

21. Chang WR, Etsion I, Bogy DB (1987) An elastic-plastic model for the contact of rough surfaces. J Tribol-T Asme 109(2): 257. https://doi.org/10.1115/1.3261348

22. Dražumerič R, Badger J, Roininen R, Krajnik P (2020) On geometry and kinematics of abrasive processes: The theory of aggressiveness. Int J Mach Tool Manu 154:103567. https://doi.org/10.1016/.ijmachtools.2020.103567

23. Preston FW (1927) The theory and design of plate glass polishing machines. J Soc. Glass Tech 11(1):214-256. 


\section{Figures}

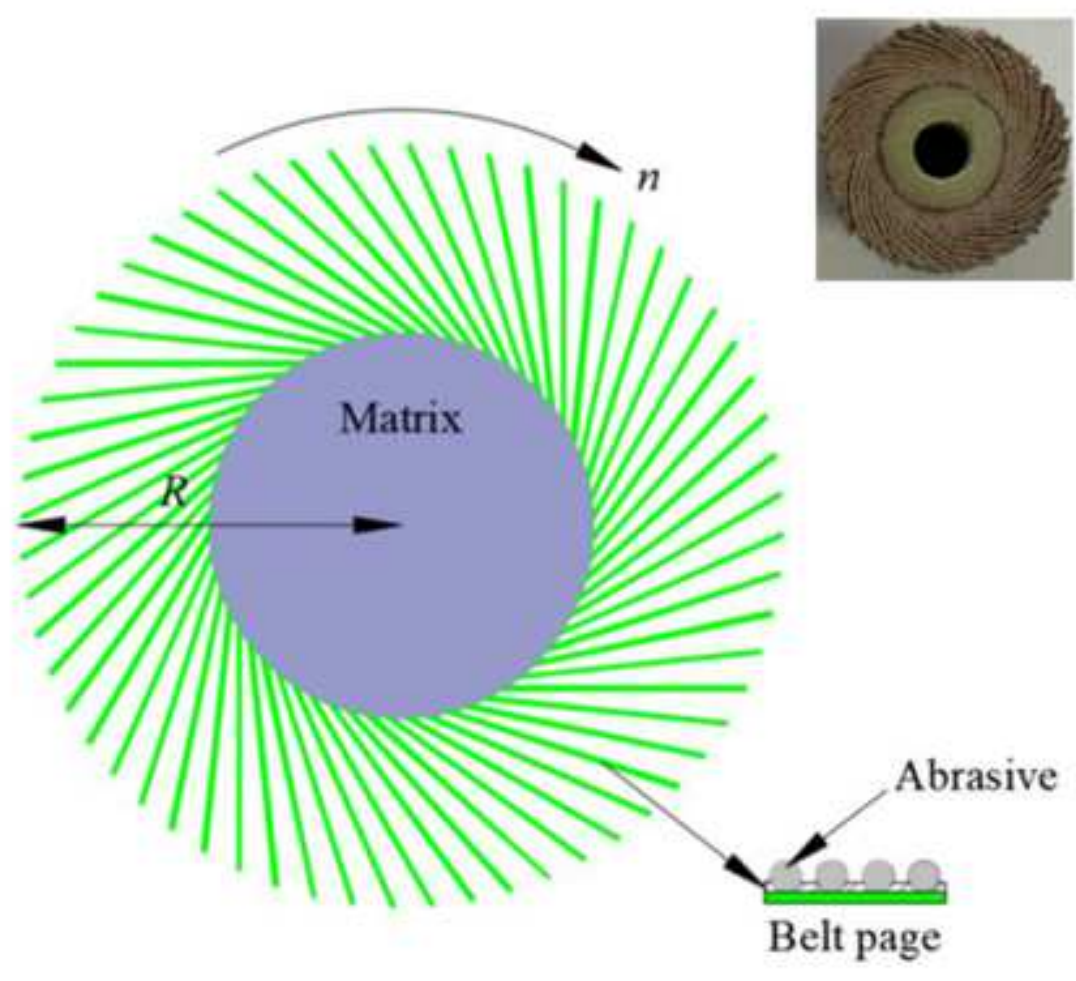

Figure 1

Structure of abrasive belt flap wheel
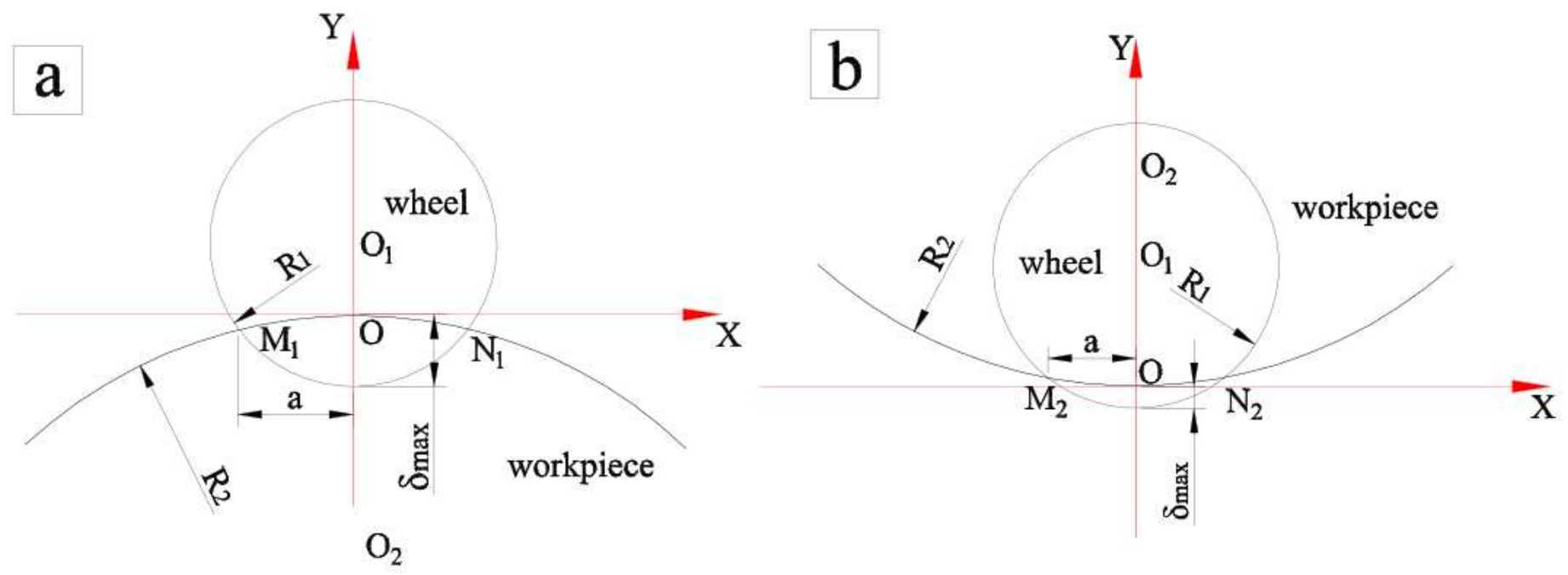

Figure 2

Contact pressure between abrasive belt flap wheel and workpiece 


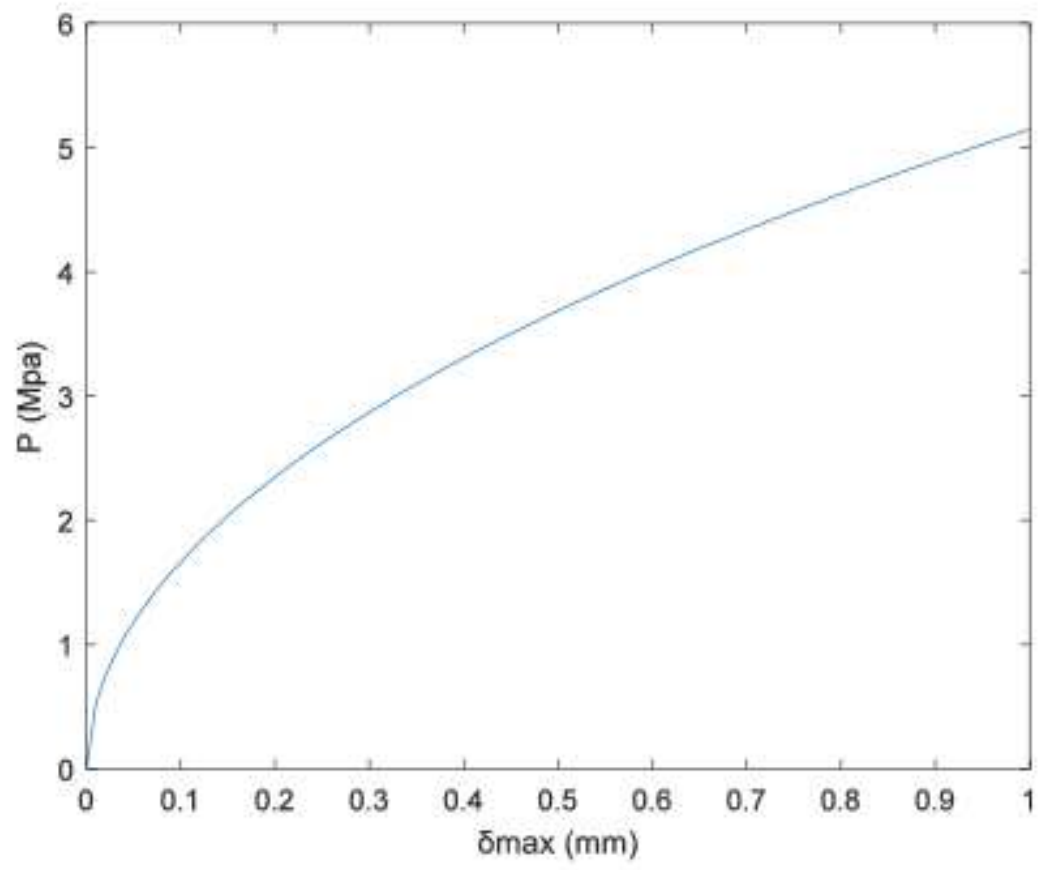

\section{Figure 3}

The relationship between contact pressure and deformation
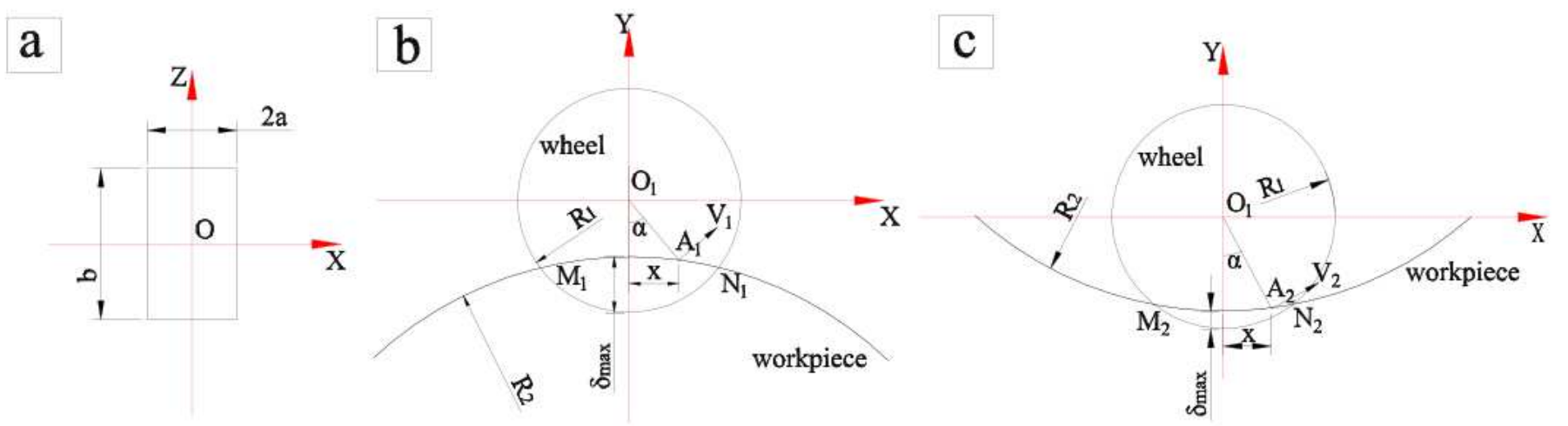

Figure 4

Relative motion speed bewtween abrasive belt flap wheel and workpiece 

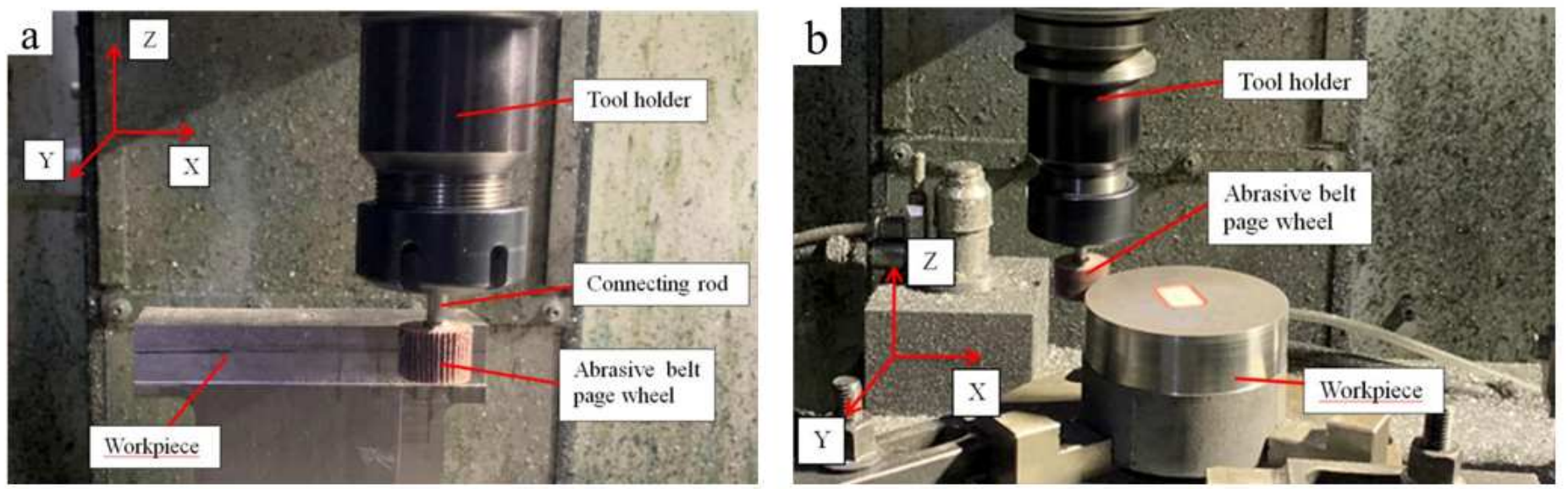

Figure 5

experimental platform

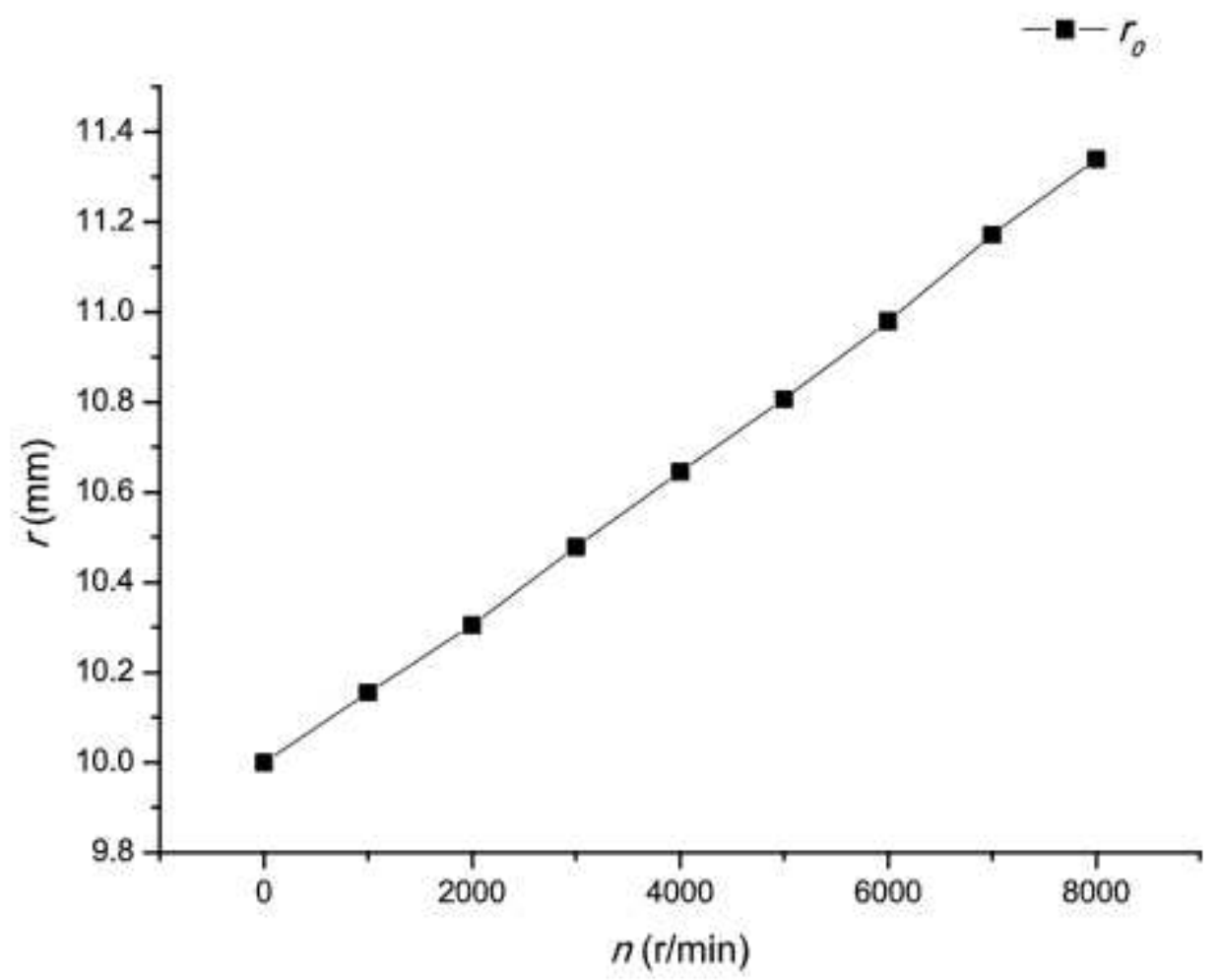

Figure 6

Relationship between $\mathrm{r} 0$ and $\mathrm{n}$ 

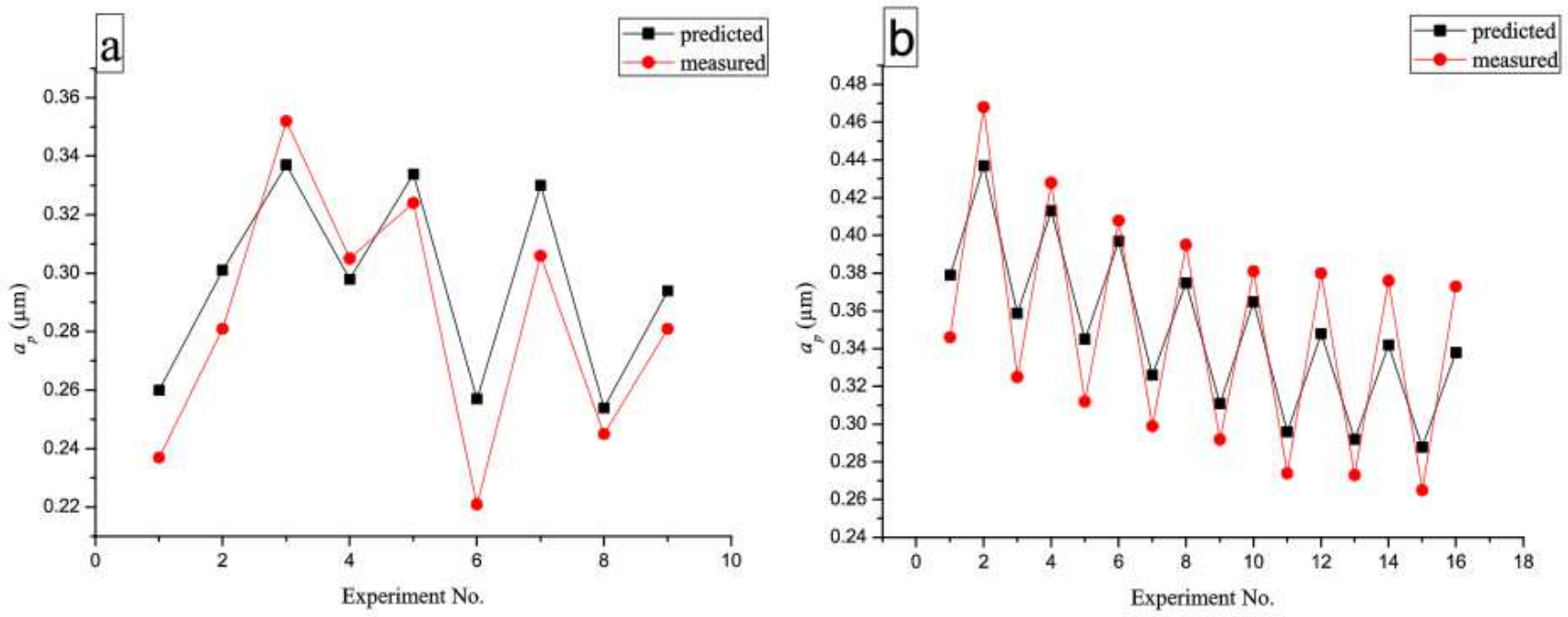

Figure 7

Comparison of measured-predicted values
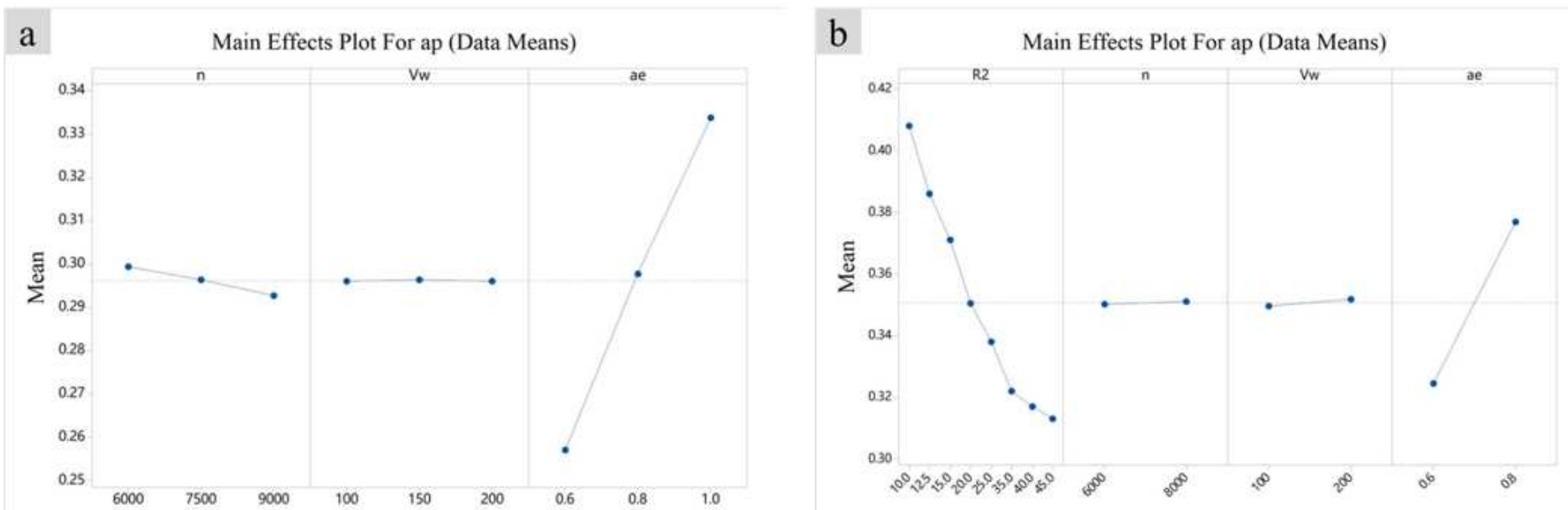

Figure 8

Main effects for each parameter 